\title{
General practice and brief psychotherapy: a novel psychiatric training post
}

\author{
Jonathan Scott
}

Many psychiatrists now work successfully in the primary care setting. Although a primary care post might be considered to be a useful experience by most trainees, few undertake such an attachment, owing to lacked opportunities and concern that such a placement would delay career progress or be at the expense of psychiatric subspeciality experience (Burns, 1994). For general practice posts to be integrated into psychiatric training, these concerns need to be addressed. One solution has been a post shared with general psychiatry (Balmer, 1993). This paper describes an alternative approach, a post combining subspeciality experfence in psychotherapy within the practice setting, with working as a general practitioner (GP) trainee.

\section{The post}

The placement was as part of the Charing Cross training scheme. where each post lasts nine months. By prior agreement between the rotation tutor, general practice trainer and myself the sessions were divided as follows: five or six (depending on weekend rota) in regular surgeries, two for cognitive-behavioural or brief psychotherapy (including supervision), one attending the vocational training scheme (VTS) and one for further training in psychiatry/research. I did my own home visits and participated in the practice on-call rota.

The practice was in Barnet, an outer London suburb with a relattvely stable population. It was non fund-holding, split on two sites and had personal lists. There were three full-time and one part-time partners. They were used to having a GP trainee. Contact with psychiatry was by referral to the local unit, within a District General Hospital, although emergencies were seen by a crisis intervention team. A community psychiatric nurse counsellor attended a weekly session.

\section{The experience}

\section{General practice work}

Like others (Balmer, 1993) I found that the relationship with the trainer was supportive, informal and very helpful. I sat in with him for the first three weeks, then discussed all patients at the end of, or during surgery. I was struck by his considerable knowledge of patients' lives and background, and the value of this in treatment. The important role of other members of the primary care team also became apparent. My medical knowledge came back quickly and my appointment times gradually reduced from fifteen to ten minutes, although close supervision and support remained essential. During emergency visits I was accompanied for the first three months, and a partner always remained available.

I found significant differences between consultations in general practice and psychiatry. The atmosphere in general practice was more informal and intimate. Patients were often surprised to find emotional issues addressed and had their 'defences down', making it particularly important to be sensitive to their mental state and to avoid a predetermined agenda. Feedback about patients was far more detailed due to regularity of contact and informal discussion with other staff. The VTS and a two-day residential course on the consultation were a helpful forum in which to consider these issues. Although others have found this emphasis on interpersonal skills a repetition of psychiatric training (Burns et al, 1994), I found that the unique aspects of general practice enabled me to reflect more effectively on my own consultation style, and to become more sensitive to the needs and wishes of patients in all settings.

I was struck by the level of ongoing support that could be provided by regular surgeries and focused particularly on patients with psychological problems. Seven patients attended over three to six consultations each, primarily for problemsolving counselling. Four had clearly defined problems and a successful outcome. Typical was a man in his fifties who was depressed and had 
not come to terms with a forced change in his employment situation. In addition to discussing medication, he valued the opportunity to be open about his feelings and look at practical solutions, although he certainly would not have engaged in more formal psychotherapy. Eleven others formed a less intense relationship but were able to look at issues relating to their psychiatric problems over a number of consultations. Even when patients were attending for separate episodes of illness, it was generally possible to observe an emerging, non-threatening relationship in which any subsequent psychological problems might be addressed.

I made surprisingly few referrals to psychiatry. Of particular value was the crisis team as they quickly took over the management of two patients who needed immediate and intensive treatment. Otherwise I sought to treat patients myself, but this required time, enthusiasm and consultant supervision. Two patients, already under the care of the psychiatrists, attended frequently and clearly valued my advice.

\section{Psychotherapy}

Referrals suitable for brief (12-20 session) psychotherapy were requested from the GPs. Initially there were relatively few referrals, in marked contrast to the frequent requests for informal advice about a wide variety of patients. Discussion with the trainer confirmed that the GPs needed time to gain confidence in me, and that there was a general reluctance of patients to engage in a new, relatively short therapeutic relationship, particularly as they often knew their own doctor well. During the post the practice counsellor built up a waiting list, yet considered only one patient appropriate to refer on. He mainly saw those in crisis needing very brief treatment, and those needing joint treatment. The role of an intermediate length treatment took time to establish.

Five patients were ultimately seen for psychotherapy. A number came who would not have gone to the psychiatry department, and all appreciated being seen in the familiar surroundings of the surgery. During the period I saw them it was agreed that their own GP (for my patients the trainer) would deal with medical problems.

Psychotherapy supervision was time consuming as I saw the analytic and cognitive therapy supervisors away from the practice and on separate sites. Although the trainer or VTS provided supervision for the non-psychotherapy patients, it was valuable to discuss alternative formulations for these patients with both supervisors.

\section{Comment}

Burns et al (1995) found that psychiatric trainees did not show any changes in consultation style after six months in general practice. However, the research assessment involved only a single diagnostic interview and may not have been sensitive enough to detect subtle changes. The comments of trainees (Burns, 1994) suggest that the GP setting offers considerable potential to improve interpersonal skills. The psychotherapy component of this job served to focus on these areas more intensely through supervision and experience, and by providing insights into the GPs' different therapeutic styles which were, I feel, reflected in their overall case load.

Direct primary care experience, if more widespread, would improve liaison by providing psychiatrists with first-hand knowledge of the complex dynamic operating in general practice. On the one hand, the GP-patient relationship is unique, being long-term, patient-led and with almost immediate access, and GPs are particularly skilled in balancing the emotional, physical and social needs of their patients. This means that many patients rely heavily on their GP, and that the GPs have a vast knowledge of patients and their families, which is rarely considered by psychiatrists. On the other hand, up to $46 \%$ of GP referrals to psychiatry are to take over management, a far higher proportion than for any other speciality (Coulter et al, 1989). This situation reflects the relative lack of current liaison with psychiatrists (Tyrer et al, 1990) and, from my experience, the heavy demands of psychiatric patients.

Before starting this placement, I had already passed the MRCPsych and had some psychotherapy experience, both big advantages enabling me to respond more adequately to some of the requests for advice by the GPs, and to the very varied demands of the post. Such GP posts would be most beneficial for those with a similar level of experience. Having a psychiatric trainee means more work for GP trainers and will probably be a long-term commitment, because VTS and psychiatric rotations usually do not run in parallel and psychiatric and GP trainees cannot easily interchange.

The psychotherapy component would be most valuable if a meeting was set up with all the GPs and any counsellors in the practice to define how this would be useful within the particular practice, to set criteria for patients and to make everyone fully aware of the opportunities of the placement. The process would become much smoother if a regular post was set up within a practice and patients could be identified and ready for the start of a new trainee's attachment.

General practice experience offers substantial benefits to psychiatric trainees' personal skills, 
clinical experience and knowledge, and should be more widely available. It is also likely to result in improved liaison with GPs. Combining this with psychotherapy experience reinforces many of these training benefits and provides unique subspeciality training.

\section{References}

BALMER, S. (1993) Experience of general practice by a psychiatric trainee. Psychiatric Bulletin, 17, 422-423.

BURNS. T. (1994) Training for psychiatrists in general practice. In Psychiatry and General Practice Today (Eds I. Pullen, G. Wilkinson, A. Wright, et af. London: Royal College of Psychiatrists and Royal College of General Practioners.
-, Silver, T., Freeung, P., et al (1994) General practice training for psychiatrists. Psychiatric Bulletin, 18, 286288.

-. MacDonald, L., SibBald, B., et al (1995) Educational assessment of general practice experience for psychiatric trainees. Medical Education, 29, 159-164.

COULTER, A., NOONE, A. \& GOLDACRE, M. (1989) General practitioner referrals to specialist outpattent clinics. I: Why general practitioners refer patients to spectalist clinics. British Medical Journal, 229, 304-308.

TYRER, P., FERGUSON, B. \& WADSWORT,, J. (1990) Lialson psychiatry in general practice: the comprehenstve collaborattive model. Acta Psychiatrica Scandinavica. 81, 359-363.

Jonathan Scott, Senior Registrar, The Three Bridges Regional Secure Unit, Uxbridge Road, Southall, Middlesex UB1 3EU

\section{College Seminars Series

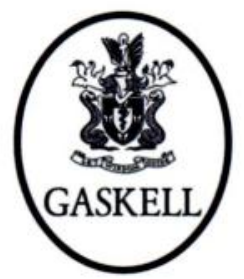 \\ Seminars in \\ Liaison Psychiatry \\ Edited by Elspeth Guthrie and Francis Creed}

Moving from the psychiatric in-patient and out-patient settings to the general medical wards can be disorientating and difficult. The clinical problems are different. In this text, recognised experts in liaison psychiatry guide the trainee through the various difficulties of interviewing, assessing and formulating the psychological problems found in patients in general medical units. $f 15.00,312$ pp., 1996, ISBN 0902241958

Available from good bookshops and from the Publications Department, Royal College of Psychiatrists, 17 Belgrave Square, London SWIX 8PG. Credit card orders can taken over the telephone $(+44(0)$ I $71-2352351$, extension 146).

The latest information on College publications is on the INTERNET at http://www.demon.co.uk/rcpsych/ 